\title{
Desafios na Implantação de Cursos a Distância
}

\section{Challenges in the Implementation of}

Distance Education Courses

\section{Luciana Senter ${ }^{1}$ \\ Gislene Miotto Catolino \\ Raymundo*2}

${ }^{1}$ Instituto Federal de Santa Catarina, Campus Xanxerê. R. Euclides Hack, 1603, Veneza - Xanxerê - SC - Brasil. ${ }^{2}$ Centro de Referência em Formação e EaD do Instituto Federal de Santa Catarina. R. Duarte Schutel, 99 - Centro, Florianópolis - SC - Brasil. gislene.miotto@ifsc.edu.br

\section{Resumo}

Este estudo teve como objetivos investigar, no Campus Xanxerê do IFSC, quais os desafios enfrentados para a oferta de cursos na modalidade de Educação a Distância (EaD) e como o campus se mobiliza para a construção de saberes necessários à oferta de cursos dessa modalidade. Realizou-se pesquisa bibliográfica e documental, além de entrevistas com gestores e enquetes com servidores. Para selecionar os sujeitos nesta pesquisa, partiu-se do pressuposto de que eles constituem atores que vivenciam as possibilidades e necessidades para oferta de cursos na modalidade EaD no contexto institucional. A análise dos documentos e dos dados coletados permitiu identificar que, entre as maiores dificuldades enfrentadas para a oferta própria em EaD, estão a falta de capacitação dos profissionais e a elaboração de materiais didáticos, além da falta de orientações claras para a estruturação de projetos pedagógicos de cursos para esse tipo de oferta. Verificou-se que, nesse campus, a EaD ainda está nos primeiros passos, mas os servidores estão mobilizados para solidificar a Educação a Distância em um futuro bem próximo.

Palavras-chave: IFSC Campus Xanxerê, Cursos a Distância, Desafios. 


\section{Challenges in the Implementation of Distance Education Courses}

\section{Abstract}

The objective of this study was to investigate, at IFSC Xanxerê campus, the challenges faced in the implementation of Distance Education (DE) courses and how the campus is structured to build the knowledge needed to make courses available in this modality. Bibliographic and documentary research were carried out, in addition to interviews with administrators and polls with the staff. It was assumed, that the selected subjects in this research were those who understand the possibilities and needs to offer courses at a distance in the institutional context. The analysis of the documents and the data collected showed that among the greatest difficulties in offering DE courses are the lack of professional training, the design of instructional materials, and also, the lack of clear guidelines for structuring pedagogical projects for this type of courses. It has been found that, on this campus, DE is still in its first steps, but staff are committed to institutionalize Distance Education in the very near future.

\section{Keywords: IFSC Xanxerê Campus, Distance Education courses, Challenges.}

\section{Introdução}

A Educação a Distância $(E a D)$ é uma realidade cada dia mais frequente entre os estudantes, especialmente para os que também são trabalhadores. Essa modalidade tem se tornado mais atraente, entre outros motivos, pela flexibilidade de locais e horários em que o aluno pode desenvolver suas atividades. De acordo com a Associação Brasileira de Educação a Distância (ABED, 2015), mais de 55\% dos alunos dos cursos presenciais com carga horária a distância do país são trabalhadores. Também nos cursos totalmente a distância, mais de $65 \%$ dos estudantes são trabalhadores.

A Educação a Distância possui relevância social muito importante, pois permite o acesso ao sistema daqueles que vêm sendo excluídos do processo educacional superior público devido à distância física das universidades ou à indisponibilidade de tempo nos horários tradicionais de aula. O ensino a distância constitui-se em uma modalidade fundamental de promoção de oportunidades, visto que muitos indivíduos, apropriando-se desse tipo de ensino, podem concluir um curso superior de qualidade e abraçar novas oportunidades profissionais (Alves, 2011).

Nesse sentido, várias instituições de ensino têm demonstrado interesse em utilizar os mais diferentes modos de organização e de modelos pedagógicos para oferta de cursos a distância para níveis de escolaridade que abrangem desde cursos de curta duração até cursos de pós-graduação, alcançando um número cada vez maior de estudantes das mais diversas localidades.

No Instituto Federal de Santa Catarina (IFSC) não é diferente. A Lei n 11.892, de 29 de dezembro de 2008, que cria a Rede Federal de Educação Profissional, Científica e Tecnológica, em seu Art. $2^{\circ}$, determina que

Os Institutos Federais são instituições de educação superior, básica e profissional, pluricurriculares e multicampi, especializados na oferta de educação profissional e tecnológica nas diferentes modalidades de ensino, com base na conjugação de conhecimentos técnicos e tecnológicos com as suas práticas pedagógicas, nos termos desta Lei (Brasil, 2008). 
A Educação a Distância no IFSC, até 2013, como uma das estratégias para o processo de institucionalização dessa modalidade no contexto institucional, contava com um Departamento de EaD subordinado à Pró-Reitoria de Ensino. Com os esforços da instituição e dos servidores envolvidos nessa modalidade para construir um modelo de Educação a Distância, surgiu a ideia da criação de um Centro de Referência em Formação e Educação a Distância (Cerfead), ao qual o Departamento de EaD está vinculado atualmente. Para a implantação desse Centro, foi aprovada pelo Conselho Superior, em fevereiro de 2014, por meio da Resolução n 42/2013/Consup, que determina modificação no marco regulatório da instituição, especialmente no Regimento Geral.

Esse Centro atua na implementação e consolidação da Política de Formação do IFSC e na institucionalização da Educação a Distância em seus 22 campus. Sua finalidade compreende: formação e qualificação dos servidores do IFSC para o exercício de suas atividades, conforme as finalidades previstas na lei de criação dos institutos federais; formação dos servidores da rede pública de ensino para atender às diretrizes estabelecidas em lei; ampliação e consolidação da oferta formativa dos campus do IFSC por meio da EaD, utilizando metodologias inovadoras e sempre articuladas aos objetivos e metas institucionais. Nessa perspectiva, o Centro atua nas áreas de formação de formadores, gestão pública, tecnologias educacionais e estratégias para consolidação do processo de institucionalização da modalidade de Educação a Distância em seus campus. Também se tornou instrumento para a ampla socialização do conhecimento para o desenvolvimento do indivíduo em seu contexto social e para promover a reflexão sobre a construção da identidade e saberes docentes do IFSC (IFSC/Cerfead, 2017).

Considerando que a instituição vivencia o processo de institucionalização da Educação a Distância em seus campi, o presente estudo busca verificar quais são os conhecimentos necessários para subsidiar a oferta do ensino a distância no IFSC, especialmente no campus Xanxerê, localizado na região oeste do Estado de Santa Catarina, que oferta cursos nessa modalidade desde 2015. Todos esses cursos são de origem de outros campi, ou seja, o planejamento e a organização de oferta são de responsabilidade de outros campi; assim, poucos servidores do campus Xanxerê tiveram oportunidade de vivenciar o processo de oferta de um curso na modalidade a distância, especialmente a elaboração do projeto pedagógico.

Um dos primeiros procedimentos para qualquer oferta de curso é a elaboração dos projetos pedagógicos de curso. Nesse sentido, para ofertar cursos em Educação a Distância os campi devem produzir ou alterar os projetos pedagógicos desses cursos; para isso, devem apropriar os conhecimentos legais, pedagógicos e tecnológicos para o planejamento e a execução desses projetos.

Dessa forma, esta pesquisa, de cunho bibliográfico, documental e com entrevistas e enquetes realizadas respectivamente com os gestores e servidores, permitiu identificar os desafios e as possibilidades enfrentadas para a oferta de cursos na modalidade EaD no campus Xanxerê do Instituto Federal de Santa Catarina.

\section{Metodologia}

O presente estudo baseou-se na pesquisa bibliográfica e documental sobre os dados do IFSC - Campus Xanxerê, legislação da EaD, resoluções internas do IFSC, além de entrevista com gestores do campus (direção geral e coordenação do Núcleo de Educação a Distância - NEaD) e realização de enquete, por meio de questionário com perguntas abertas e fechadas aplicado aos servidores. A entrevista consistia das seguintes perguntas: 1) Quando se iniciaram as atividades do NEaD no campus e quantos alunos foram atendidos até o momento?; 2) Quais os cursos ofertados no campus até o presente momento?; 3) Quais as principais dificuldades de estrutura física e recursos humanos para a implementação efetiva de cursos próprios ofertados pelo campus?

Além das entrevistas com os gestores, outras informações foram coletadas com a realização de pesquisa em documentos disponíveis no campus, como portarias internas do IFSC publicadas na internet. 
A enquete foi realizada por meio de um questionário contendo 10 perguntas destinadas aos servidores do campus, entre técnicos administrativos e docentes. A aplicação do questionário foi por formulário eletrônico do Google Docs e manteve o anonimato dos colaboradores. As perguntas e respostas dessa enquete estão relacionadas no tópico Resultados e Discussão.

Para o desenvolvimento desta pesquisa, optou-se por uma abordagem de cunho qualitativo, pois dessa forma há maior possibilidade de analisar e interpretar as opiniões, conhecimentos e atitudes expressas nos dados coletados.

Chizzotti (2006, p. 28-29) contribui para constituir o referencial sobre pesquisa qualitativa quando afirma que:

\begin{abstract}
O termo qualitativo implica uma partilha densa com pessoas, fatos e locais que constituem objetos de pesquisa, para extrair desse convívio os significados visíveis e latentes que somente são perceptíveis a uma atenção sensível. Após esse tirocínio, o autor interpreta e traduz em um texto zelosamente escrito, com perspicácia e competências científicas, os significados patentes e ocultos do seu objeto de pesquisa.
\end{abstract}

A abordagem quantitativa também é empregada a fim de analisar os números fornecidos pela pesquisa. O quadro de servidores do campus em estudo é composto por docentes, técnicos administrativos em educação (TAEs) do Departamento de Ensino, Pesquisa e Extensão - DEPE e técnicos administrativos do Departamento de Administração - DAM. Os sujeitos pesquisados foram classificados de acordo com o setor de alocação, uma vez que cada setor desempenha importante contribuição, direta ou indiretamente, para a educação no campus, especialmente para a oferta de cursos.

\title{
3. Resultados e Discussão
}

\subsection{Entrevista com gestores}

A entrevista com os gestores do campus, especialmente a direção geral e a coordenação do NEaD, sobre a oferta de cursos a distância no campus obteve as seguintes informações: a) iniciou-se em 2015 a oferta de cursos em EaD, sendo atendidos até o momento cerca de 130 alunos em cursos de formação inicial e continuada de idiomas (Inglês e Espanhol) e curso de especialização em Educação Profissional e Tecnológica; b) no que diz respeito às dificuldades encontradas para a implementação efetiva de cursos próprios ofertados pelo campus, ambas as entrevistadas concordam que a ausência de regulamentação referente à carga horária no planejamento docente, bem como a falta de conhecimentos e capacitação tanto por parte dos docentes como dos técnicos administrativos, são os principais entraves para o avanço dessa modalidade no campus; c) outro ponto destacado foi a falta de estrutura física e tecnológica, que é problema também do ensino presencial, pois o aumento da oferta de cursos presencial e a distância no campus requer especialmente a ampliação da estrutura física.

\subsubsection{Enquete com os servidores do campus}

Do total de servidores do campus, 36 são docentes, 10 TAEs que estavam alocados no DEPE e 11 TAEs alocados no DAM. Foram obtidos 26 questionários respondidos, sendo 17 de docentes (65,4\%), 5 de TAEs do DEPE $(19,2 \%)$ e 4 de TAEs do DAM $(15,4 \%)$. 
Os servidores foram indagados sobre sua forma de contato com cursos EaD; os resultados podem ser vistos na Figura 1. Percebe-se que a maioria dos participantes (20), cerca de 77\%, já atuou como aluno de algum curso em EaD. Esse resultado corrobora os dados do Censo da ABED (2005; 2015). Enquanto em 2005, somente na região Sul do Brasil, as matrículas totalizavam 14.930 alunos no ensino a distância, em 2015 esses números chegaram a 5.048.912 alunos nas mais variadas áreas de conhecimento, níveis acadêmicos e tipos de cursos, evidenciando o crescente número de matrículas nessa modalidade de ensino. É possível verificar também na Figura 1 a pouca experiência na docência em EaD no campus, necessitando capacitação para esse fim.

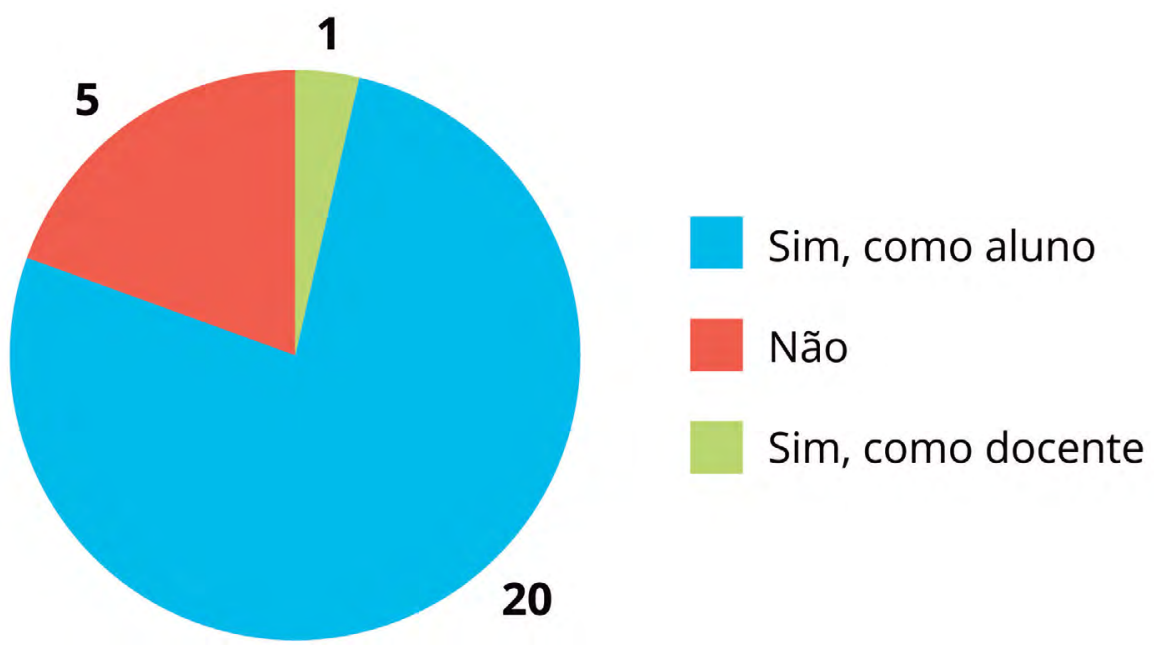

Figura 1: Distribuição da experiência dos servidores pesquisados em cursos EaD.

Perguntou-se aos servidores se eles haviam participado de algum curso de capacitação para atuar em EaD. Constatou-se que os cursos com participação dos servidores são os ofertados pela própria instituição, por meio do Cerfead, com o intuito de ampliar os conhecimentos e saberes sobre a oferta de cursos nessa modalidade. Os resultados estão discriminados na Tabela 1.

Tabela 1: Distribuição da participação em capacitação para atuar na EaD, de acordo com cada categoria de participante

\begin{tabular}{|l|c|c|c|}
\hline \multirow{2}{*}{\multicolumn{2}{c|}{ Respostas }} & \multicolumn{2}{c|}{ Categoria } \\
\cline { 2 - 4 } & Docente & TAE- DEPE & TAE - DAM \\
\hline Sim & 4 & - & 1 \\
\hline Não & 9 & 5 & 2 \\
\hline Capacitação em uso da plataforma Moodle & 1 & - & - \\
\hline FIC em EaD: princípios e orientações & 1 & - & - \\
\hline Capacitação em EaD: tutoria e monitoria & 1 & - & - \\
\hline Capacitação em EaD & - & - & 1 \\
\hline FIC: Elaboração de materiais didáticos & 1 & - & - \\
\hline
\end{tabular}

De acordo com a Tabela 1, percebe-se que, entre os servidores respondentes, os docentes foram os que mais participaram dessas capacitações. O Decreto $n^{\circ}$ 9.057/17 (Brasil, 2017) prevê, em seu Art. $1^{\circ}$, que a Educação a Distância é uma modalidade que, além da utilização de meios e tecnologias de informação e 
comunicação, ocorre com pessoal qualificado. Além disso, a Lei de Diretrizes e Bases da Educação Nacional - LDBEN (Brasil, 1996) também prevê que os profissionais da educação devem ser capacitados para o exercício da função. Nas três categorias de participantes nesta pesquisa, houve manifestação de não ter participado de cursos de capacitação; sendo assim, ressalta-se a importância do incentivo à qualificação dos servidores em EaD por meio de capacitações coletivas ou individuais.

Quanto à pergunta "Você se sente capacitado para atuar (como docente, tutor, pedagogo, técnico em informática, registro acadêmico ou de outra forma) em um curso na modalidade EaD?", apenas 26,9\% dos servidores pesquisados responderam que se sentem aptos para desempenhar funções mencionadas, sendo 6 docentes e 1 TAE-DAM. Esses resultados reforçam a necessidade de capacitação identificada pelas gestoras entrevistadas. A Figura 2 apresenta dados detalhados por categoria.

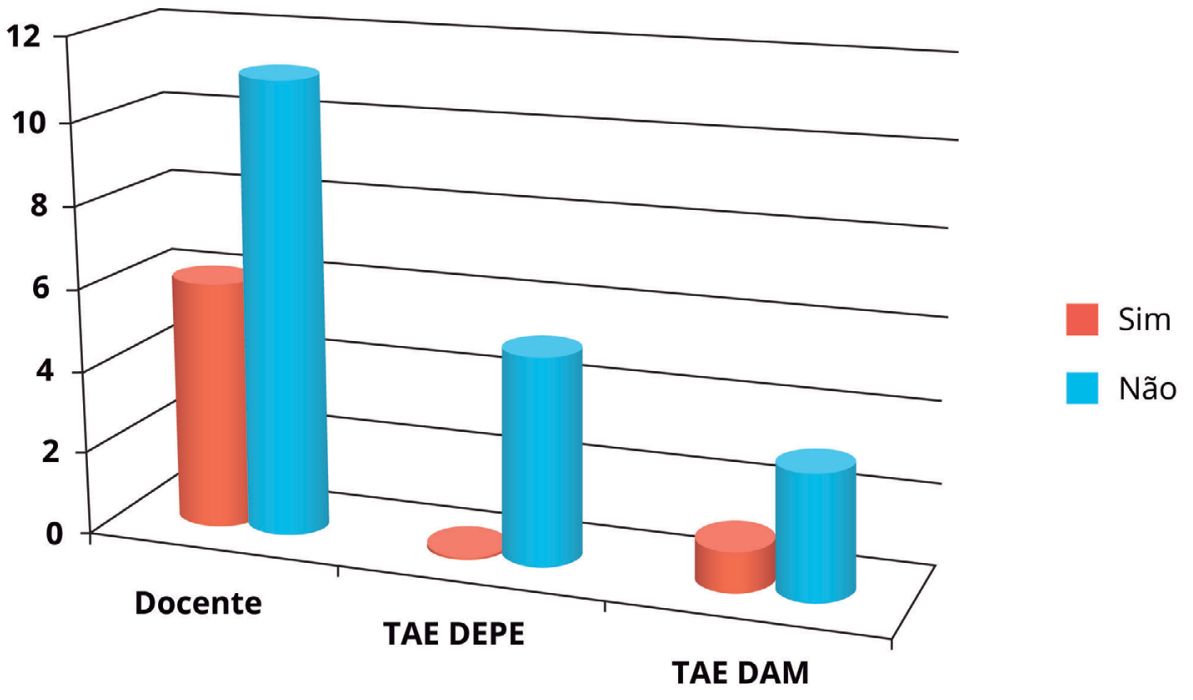

Figura 2: Distribuição por categoria quanto à resposta sobre a pergunta "Você se sente capacitado para atuar em um curso na modalidade EaD?"

Isso pode ser explicado pelo fato de que parcela significativa dos docentes, especificamente da área técnica, tem formação em bacharelado ou tecnologia e não possui forte embasamento nas áreas de licenciatura. Em um dos relatos da enquete, um(a) servidor(a) com licenciatura relatou que não foi capacitado para atuar em EaD durante seu curso de graduação. De acordo com Alves (2011), essa situação se justifica porque a EaD só surgiu oficialmente no Brasil em 1996, por meio da LDBEN (Brasil, 1996), em seu Art. 80, porém somente foi regulamentada em 20 de dezembro de 2005 pelo Decreto $n^{\circ} 5.622$ (Brasil, 2005). Assim, os docentes do campus com formação anterior a essa data não tiveram acesso ao ensino em EaD em seus cursos de graduação. Breneer et al. (2014) corroboram essa realidade, afirmando que a formação de professores precisa prepará-los para a inovação tecnológica e suas consequências pedagógicas. É possível inferir que muitos professores não tiveram oportunidade de receber nenhuma formação para interagir com as tecnologias necessárias para o exercício da modalidade a distância e, em muitos casos, há certo receio em relação a essas tecnologias.

O uso adequado dessas ferramentas tecnológicas constitui condição para melhorar a qualidade do ensino e adequá-lo à realidade. Dessa forma, o grande desafio atual para os professores é o domínio dessas tecnologias e o conhecimento do que elas têm a oferecer para viabilizar o processo de ensinar e aprender. 
Moran (2003, p. 45), ao analisar essa situação, afirma que:

\begin{abstract}
Precisamos reinventar a forma de ensinar e aprender presencial e virtualmente, diante de tantas mudanças na sociedade e no mundo do trabalho. Os modelos tradicionais são cada vez mais inadequados. Educar com novas tecnologias é um desafio que até agora não foi enfrentado com profundidade. Temos feito apenas adaptações, pequenas mudanças. Agora, na escola e no trabalho, podemos aprender continuamente, de forma flexível, reunidos numa sala ou distantes geograficamente, mas conectados através de redes.
\end{abstract}

Nesse sentido, o uso das novas tecnologias da informação e comunicação aponta aos docentes que há outras maneiras de ter acesso a situações de aprendizagem e procedimentos de ensino e que, por mais que tenhamos a nostalgia de outros instrumentos e procedimentos de ensino, podemos afirmar que, nesse contexto, os diversos tipos de mídia caracterizam-se como cúmplices imprescindíveis que possibilitam a criação de novos recursos didáticos e viabilizam a interatividade na construção do conhecimento. Portanto, a capacitação de todos os atores envolvidos no processo de oferta de cursos na modalidade a distância é imprescindível e foi devidamente constatado nesta pesquisa.

Lengler et al. (2016) afirmam que os docentes devem potencializar suas competências técnicas relacionadas ao domínio pedagógico e ao domínio comunicativo e às competências comportamentais relacionadas ao domínio técnico e pedagógico.

Esta pesquisa também constatou que, em abril de 2017, o Campus Xanxerê sediou uma capacitação denominada Capacitação Moodle, ministrada aos docentes locais, no ambiente virtual institucionalizado IFSC/Cerfead, com duração de 20 horas, sendo 12 horas a distância e 8 horas presenciais. Essa é uma importante ferramenta de trabalho que medeia diferentes frentes de atuação docente e administrativa. Do total de 57 servidores do campus, 31 participaram da capacitação. É possível relacionar a presente capacitação com o resultado apresentado na Figura 2, que relata poucos servidores com a sensação de estarem capacitados para atuar em EaD, servindo como forma de resposta à falta de formação mencionada pelas entrevistadas e verificada no resultado da enquete.

Freitas (2007) destaca algumas dificuldades e limitações na Educação a Distância, como manter a equipe sempre altamente motivada, acreditando no que faz, prover cursos de formação de professores e de especialização em educação. Além disso, a formação de equipes multidisciplinares é de extrema importância; a parceria profissional entre as diversas equipes é premissa para a elaboração de vídeos, programas de computação e interações virtuais entre os diversos atores envolvidos na educação.

Também conforme a Resolução $n^{\circ}$ 1, de 11 de março de 2016, que estabelece diretrizes e normas nacionais para a oferta de programas e cursos de educação superior na modalidade a distância, "os profissionais da educação que atuarem em EaD devem ter formação condizente com a legislação em vigor e preparação específica para atuar nessa modalidade educacional" (Brasil, 2016a).

As maiores dificuldades encontradas pelo campus para a oferta de um curso próprio na modalidade a distância aparecem na Figura 3. Por meio de pergunta aberta, o servidor poderia citar mais que um ponto considerado como dificuldade para a oferta de cursos a distância. 


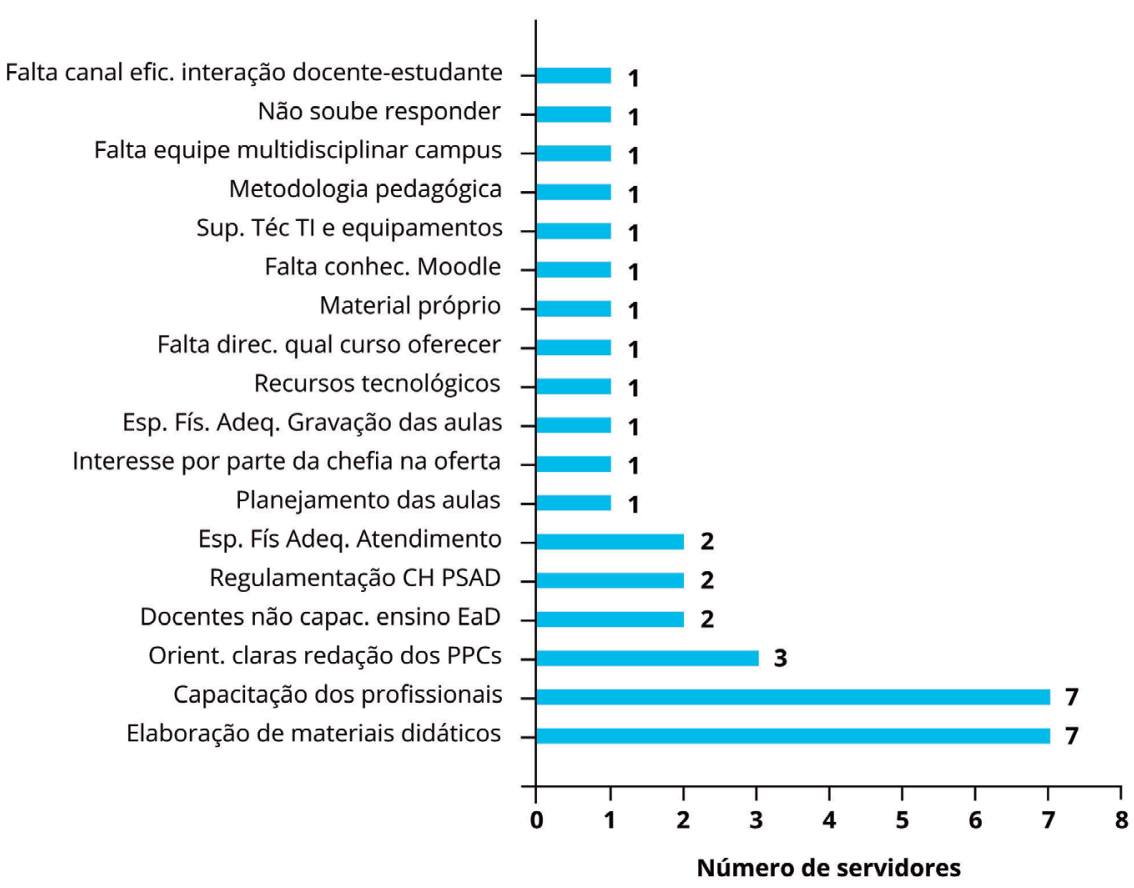

Figura 3: Dificuldades elencadas pelos servidores para a oferta de um curso próprio em EaD

Como é possível perceber na Figura 3, as dificuldades mais citadas para a oferta de um curso próprio em EaD são: falta de capacitação dos servidores e elaboração de materiais didáticos. Embora o campus tenha recebido capacitação para trabalhar na plataforma de ambiente virtual Moodle, conforme já mencionado, isso ainda é insuficiente do ponto de vista dos servidores, pois para a oferta em EaD são necessários outros conhecimentos além dos que foram veiculados nas capacitações realizadas. No entanto, deve ser ressaltado que a instituição disponibiliza, por meio do Cerfead, diversos cursos de formação inicial e continuada, como os cursos de formação inicial e continuada (FICS) de Planejamento e Desenvolvimento de Cursos na Modalidade a Distância, Tutoria e Mediação Pedagógica e de Tecnologias para a Educação. Entretanto, a capacitação depende do interesse próprio do servidor em participar do processo seletivo e da realização de cada curso.

O terceiro ponto mais citado foi a necessidade de orientações claras sobre a redação, formulação e atualização dos projetos pedagógicos de curso, especialmente no que diz respeito à inclusão de $20 \%$ de atividades a distância na carga horária total do curso. Esse ponto também foi citado na entrevista realizada com as gestoras do campus. De acordo com a legislação vigente (Brasil, 2016b), a Portaria n 1.134/16, em seu Art. $1^{\circ}$, as disciplinas poderão ser ofertadas integral ou parcialmente a distância, desde que essa carga horária não ultrapasse $20 \%$ da carga horária total do curso, observando-se que as avaliações devem ser presenciais. Destaca-se ainda que os projetos pedagógicos para Educação a Distância devem ser construídos e vivenciados em todos os momentos por todos os envolvidos com o processo educativo da escola (Veiga, 2002).

Ainda no que diz respeito às orientações específicas para a elaboração dos projetos pedagógicos de cursos, os Referenciais de Qualidade para a Educação Superior a Distância (2007) explicitam alguns itens importantes que devem constar:

Descrever como se dará a interação entre estudantes, tutores e professores ao longo do curso; quantificar o número de professores/hora disponíveis para os atendimentos requeridos pelos estudantes e quantificar a relação tutor/estudantes; informar a previsão dos momentos presenciais, em particular os horários de tutoria presencial e de tutoria a distância; informar aos estudantes, desde o início do curso, nomes, horários, formas e números para contato com professores, tutores e pessoal de apoio; informar 
locais e datas de provas e datas limite para as diferentes atividades; descrever o sistema de orientação e acompanhamento do estudante, garantindo que os estudantes tenham sua evolução e dificuldades regularmente monitoradas, que recebam respostas rápidas a suas dúvidas e incentivos e orientação quanto ao progresso nos estudos; assegurar flexibilidade no atendimento ao estudante, oferecendo horários ampliados para o atendimento tutorial; dispor de polos de apoio descentralizados de atendimento ao estudante, com infraestrutura compatível para as atividades presenciais; valer-se de modalidades comunicacionais síncronas e assíncronas; facilitar a interação entre estudantes por meio de atividades coletivas, presenciais ou via ambientes de aprendizagem; planejar a formação, a supervisão e a avaliação dos tutores e outros profissionais que atuam nos polos de apoio descentralizados, de modo a assegurar padrão de qualidade no atendimento aos estudantes; abrir espaço para uma representação de estudantes, em órgãos colegiados de decisão, de modo a receber feedback e aperfeiçoar os processos (MEC/SEED, 2007, p. 11).

Sobre se o campus Xanxerê vem se mobilizando para a adequação dos projetos pedagógicos de seus cursos já ofertados, os gestores relataram que se trata de uma situação relativamente nova na instituição; assim, há certa dificuldade para conseguir orientações concretas sobre o assunto, o que aumenta a morosidade na adequação e implementação, especialmente na modalidade a distância.

As respostas à pergunta aberta aos servidores "Para a oferta de cursos na modalidade a distância ou oferta de $20 \%$ da carga horária em EaD, o que você considera necessário (infraestrutura, pessoal, formação/capacitação, conhecimentos e outros)?" estão na Figura 4.

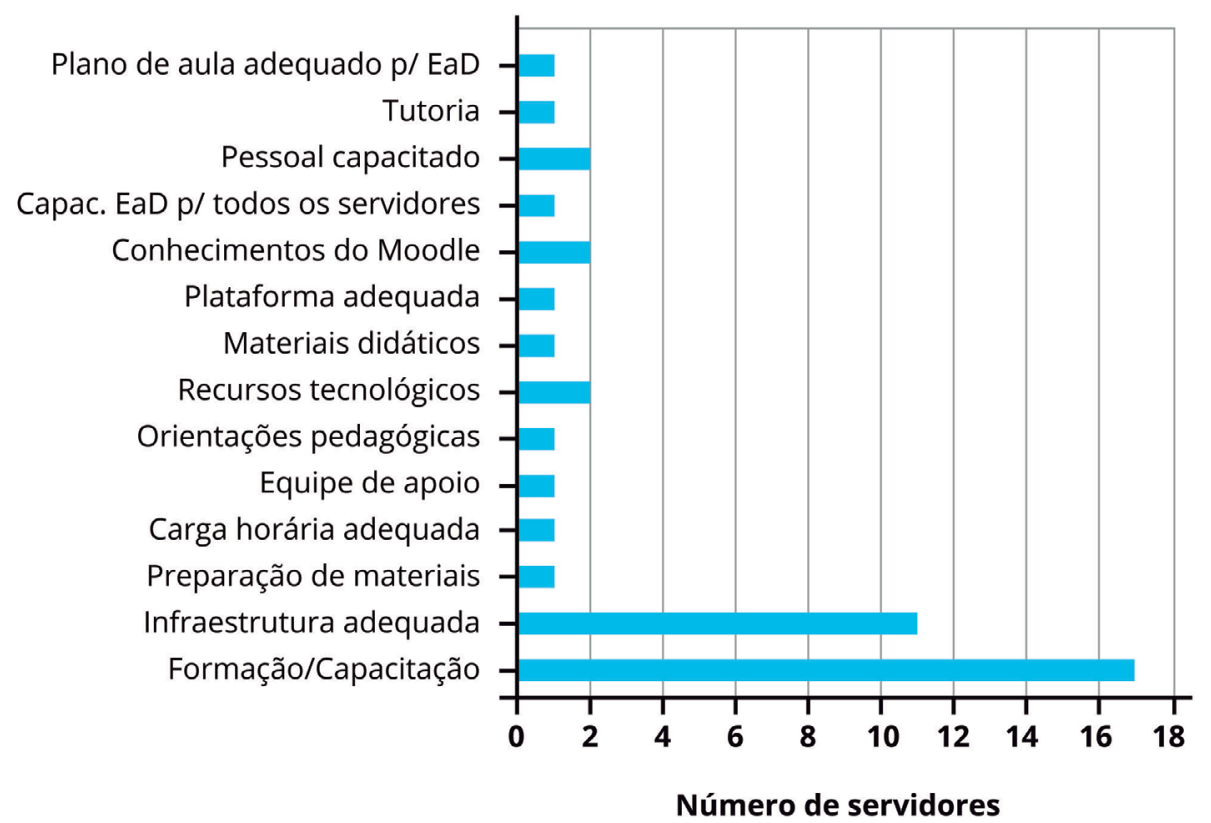

Figura 4: Necessidades para oferta em $\mathrm{EaD}$, segundo os servidores pesquisados

Os vários apontamentos realizados pelos servidores pesquisados reforçaram o que já está prescrito nos Referenciais de Qualidade para a Educação a Distância (MEC/SEED, 2007, p. 21) e na Resolução $n^{\circ} 1$, de 11 de março de 2016 (Brasil, 2016a): a necessidade de capacitação dos autores envolvidos em oferta de cursos a distância, que deve ser suprida por meio de uma política institucional de capacitação e atualização permanente desses profissionais.

Para que os professores possam (re)pensar as metodologias de ensino e elaborar materiais didáticos de qualidade no contexto das tecnologias, torna-se fundamental fomentar cursos de capacitação de professores que contemplem a formação técnico-pedagógica, a elaboração de material didático digital e o sistema de gestão, o qual dará apoio às ações nessa modalidade (Novello; Laurino, 2012). 
A questão da infraestrutura, segundo ponto mais citado, de acordo com a Figura 4, é reforçada também no depoimento da direção do campus, quando destaca que a estrutura física atual não é apenas um problema da EaD, mas também da educação presencial; ela necessita de ampliação de salas de aula e de espaço administrativo. A infraestrutura física e tecnológica compatível com a missão institucional e o apoio pedagógico, tecnológico e administrativo é uma obrigação legal (Brasil, 2016a) e deve ser oferecida de acordo com o plano de desenvolvimento institucional, as Diretrizes Curriculares Nacionais e o projeto pedagógico de curso. Os referenciais de qualidade da EaD (MEC/SEED, 2007) também exigem a infraestrutura compatível para as atividades presenciais, incluindo o material que dá suporte tecnológico, científico e instrumental aos cursos.

Quando indagados sobre os conhecimentos pedagógicos, legais e tecnológicos, cerca de $42 \%$ (11) dos servidores pesquisados responderam não terem conhecimento desses aspectos essenciais para a elaboração de propostas de novos cursos ou unidades curriculares, bem como a efetivação da EaD, conforme Figura 5.

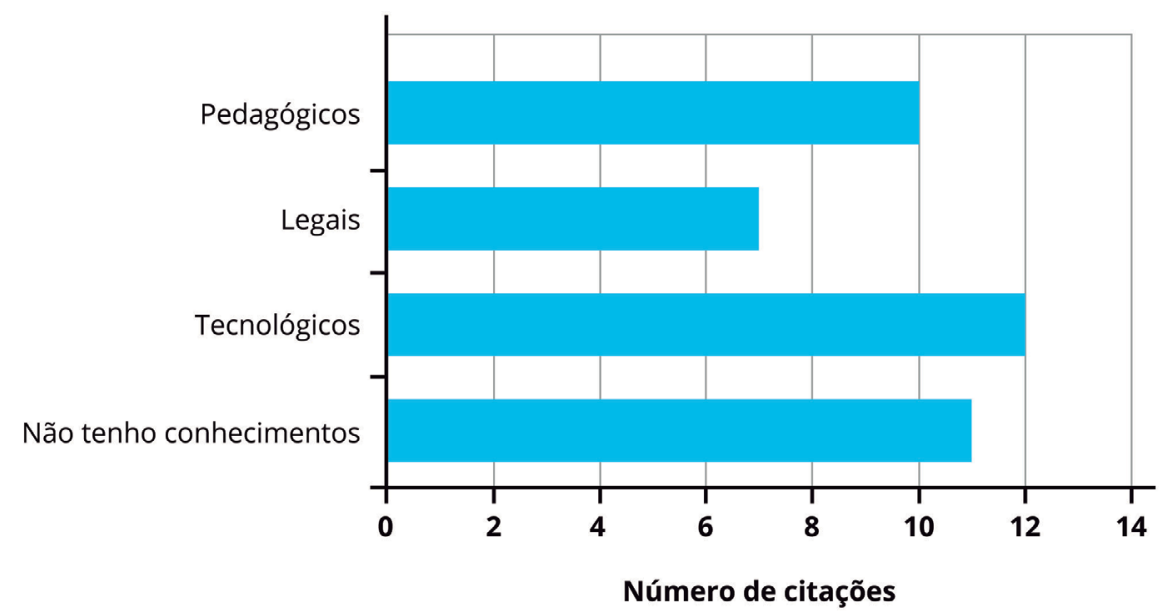

Figura 5: Conhecimentos elencados pelos servidores para realizar a oferta de curso ou unidade curricular a distância

Brenner et al. (2014) apresentam possíveis estratégias no que se refere aos desafios enfrentados pelas instituições de ensino na prática da EaD. A formação e qualificação dos professores é apontada, em diversos artigos, como um dos principais elementos que embasam o desenvolvimento pleno do ensino a distância. A formação tem por objetivo possibilitar novas alternativas de trabalho coerentes com os processos de mudança impostos pela Educação a Distância.

Novello e Laurino (2012) reforçam a importância da capacitação para o ensino a distância, relatando que muitos professores, ao voltar para a sala de aula presencial, sentem como se faltasse algo; sentem que o planejamento é menos rigoroso, que as atividades em sala são muito menos previstas, que o material poderia ser mais adequado e que a avaliação é decidida, muitas vezes, sem critérios predefinidos. Professores e alunos, ao terem acesso a materiais bem elaborados produzidos para cursos a distância, costumam trazê-los também para a sala de aula presencial.

Historicamente, os centros de ensino estão localizados nas capitais dos estados, deixando por muito tempo as regiões de interior desprovidas de acesso à educação. Com a ascensão da EaD, muitas necessidades de capacitação puderam ser atendidas, algumas das quais são apontadas pelos servidores, como está na Figura 6. 


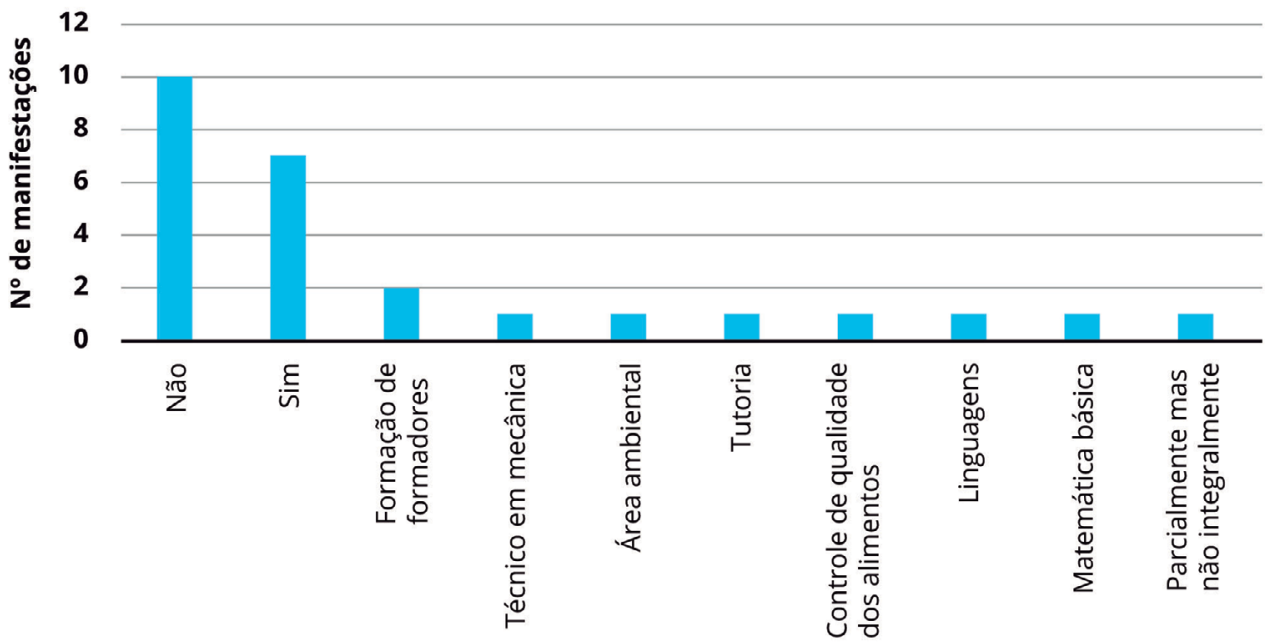

Figura 6: Manifestação de intenção na oferta de cursos ou unidades curriculares na modalidade a distância, no Campus Xanxerê

De acordo com os resultados apresentados até o momento, bem como demonstrado nas Figuras 6 e 7 , é possível verificar que a maioria dos servidores pesquisados mostra-se interessada na oferta de ensino a distância no Campus Xanxerê. As áreas de interesse indicadas na Figura 6 são variadas; nove servidores, além dos que se manifestaram com a opção sim, também indicaram opções abrangendo desde a formação de formadores à área técnica.

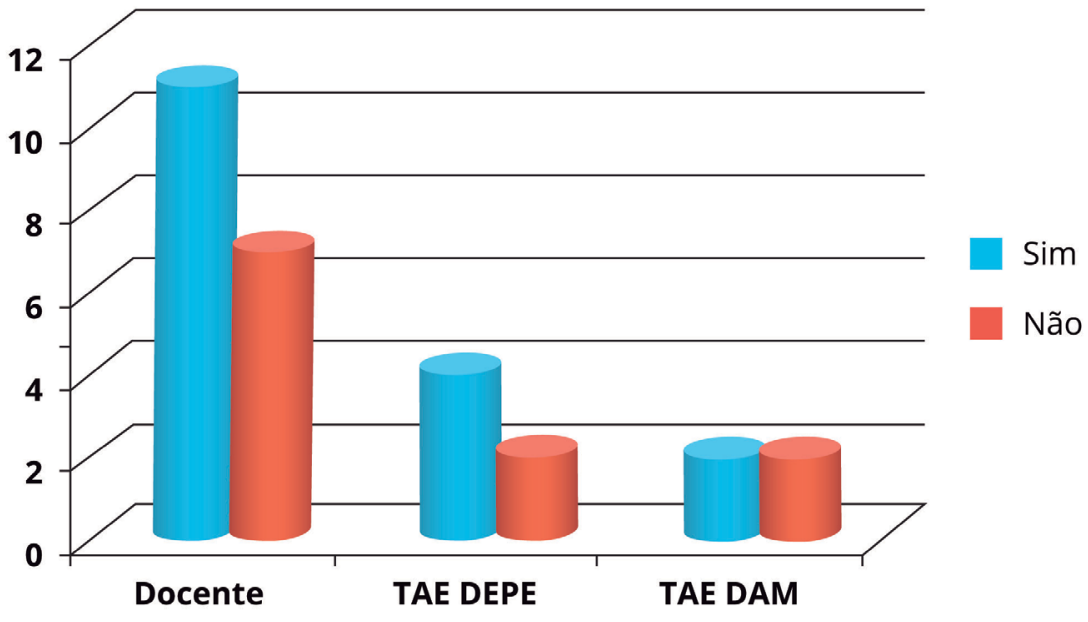

Figura 7: Manifestação de interesse de participação em um grupo de estudo para organizar a oferta de cursos EaD, no Campus Xanxerê

Medeiros (2017) comenta que a implantação da EaD de forma institucionalizada passa pelo processo de aceitação por parte dos indivíduos que vão executar tais políticas. A Figura 7 revela essa aceitação por meio da manifestação de interesse dos servidores em organizar ofertas nessa modalidade. A autora ainda lembra que o Brasil tem forte tradição na EaD no ensino superior e técnico; entretanto, a operacionalização dessa modalidade de ensino necessita de novas estratégias didático-pedagógicas para proporcionar ao aluno um aprendizado efetivo. Para isso, toda a equipe envolvida na gestão desse conhecimento deve estar disposta a se capacitar para ofertar cursos, seja como docente ou apoio técnico.

Nesse sentido, o processo de conhecimento para planejar e ofertar cursos na modalidade EaD constitui um novo espaço educativo que permite ampliar as reflexões sobre o papel das tecnologias da 
informação e comunicação na educação e possibilita a prática de novas situações didáticas específicas da modalidade a distância.

\section{Considerações Finais}

Observou-se que os desafios relatados na enquete pelos servidores para a oferta de cursos a distância no Campus Xanxerê são muito semelhantes aos elencados pelas gestoras nas entrevistas. Os principais apontamentos se referem: à falta de regulamentação da carga horária da EaD no Planejamento Semestral de Atividades Docentes (PSAD); falta de orientações claras sobre a elaboração dos projetos de curso; deficiência na capacitação para atuar em Educação a Distância e infraestrutura física e tecnológica insuficientes. Destaca-se também que apenas $26,9 \%$ dos servidores pesquisados julgam-se aptos para desempenhar uma ou mais funções na EaD (docente, tutor, apoio pedagógico, entre outros), o que justifica a necessidade de capacitação que as gestoras propuseram na entrevista.

Também foi constatado que os sujeitos pesquisados apontam várias opções de cursos que podem ser ofertados em EaD no campus em diversas áreas; cerca de 77\% desses servidores já realizaram alguma capacitação por meio da EaD.

Muitas instituições de ensino superior utilizam o Moodle como plataforma de ambiente virtual de aprendizagem, sendo possível simular várias situações da sala de aula e fazer gerenciamento dos participantes, relatórios de acesso e atividades e promover e otimizar a interação entre alunos e docentes, permitindo assim maior autonomia e aquisição de novas habilidades (Sebastião, 2015). O IFSC optou pelo uso dessa plataforma; o Cerfead realiza capacitações para os servidores da instituição, sendo possível utilizar a ferramenta tanto para o ensino presencial quanto a distância. Com a pesquisa também foi verificado que recentemente os servidores do campus receberam treinamento para trabalhar com essa ferramenta, embora ainda haja a necessidade de intensificar a capacitação desses servidores para que a modalidade EaD seja ofertada plenamente.

Para finalizar, a pesquisa destaca a necessidade de orientações para a elaboração de projetos pedagógicos de curso, embora esse estudo tenha apontado os principais caminhos a seguir, incluindo o Cerfead, que é o centro especializado em ensino a distância no IFSC e tem a missão de oferecer "apoio pedagógico à concepção, ao desenho educacional e à produção de materiais dos cursos e componentes curriculares ofertados na modalidade a distância" (Resolução CEPE/IFSC nº 04, de 16 de março de 2017, p. 9).

Portanto, por meio desta pesquisa, constatou-se que no IFSC, Campus Xanxerê, a EaD ainda está nos primeiros passos, mas não será assim por muito tempo, uma vez que os servidores estão mobilizados para que o ensino a distância seja realidade em um futuro bem próximo.

\section{Referências Bibliográficas}

ABED (2005). Censo da EAD 2005. Acesso em julho de 2017, disponível em http://www.abed.org.br/ censoead/anuario2005.pdf.

ABED. (2015). Censo da EAD 2015. Acesso em julho de 2017, disponível em http://abed.org.br/arquivos/ Censo EAD 2015 POR.pdf.

Alves, L. (2011). Educação a distância: conceitos e histórias no Brasil e no mundo. Revista Brasileira de Aprendizagem Aberta e a Distância, 10, 83-92. Disponível em http://www.abed.org.br/revistacientifica/ Revista PDF Doc/2011/Artigo 07.pdf. 
Brasil (1996). Lei n 9.394, de 20 de dezembro de 1996. Estabelece as Diretrizes e Bases da Educação Nacional. Diário Oficial da República Federativa do Brasil. Acesso em abril de 2017, disponível em http:// www.planalto.gov.br/ccivil_03/leis/19394.htm.

Brasil (2005). Decreto $n^{\circ}$ 5.622, de 19 de dezembro de 2005. Regulamenta o artigo 80 da Lei $n^{\circ} 9394$, de 20 de dezembro de 1996, que estabelece as diretrizes e bases da educação nacional. Diário Oficial da República Federativa do Brasil. Acesso em abril de 2017, disponível em http://www.planalto.gov.br/ ccivil_03/_ato2004-2006/2005/decreto/d5622.htm.

Brasil (2008). Lei n 11.892, de 29 de dezembro de 2008. Institui a Rede Federal de Educação Profissional, Científica e Tecnológica, cria os Institutos Federais de Educação, Ciência e Tecnologia, e outras previdências. Diário Oficial da República Federativa do Brasil. Acesso em abril de 2017, disponível em: http://www.planalto.gov.br/ccivil_03/_ato2007-2010/2008/lei/l11892.htm.

Brasil (2016a). Resolução n 1, de 11 de março de 2016. Conselho Nacional de Educação. Estabelece Diretrizes e Normas Nacionais para a Oferta de Programas e Cursos de Educação Superior na Modalidade a Distância. Acesso em abril 2017, disponível em http://portal.mec.gov.br/index.php?option=com docman\&view=download\&alias=35541-res-cne-ces-001-14032016-pdf\&category_slug=marco-2016pdf\&ltemid=30192.

Brasil (2016b). Portaria n 1.134, de 10 de outubro de 2016. Revoga a Portaria MEC n 4.059, de 10 de dezembro de 2004, e estabelece nova redação para o tema. Diário Oficial da República Federativa do Brasil. Acesso em junho de 2017, disponível em https://www.jusbrasil.com.br/diarios/127794688/dousecao-1-11-10-2016-pg-21.

Brasil (2017). Decreto $n^{\circ}$ 9.057, de 25 de maio de 2017. Regulamenta o Art. 80 da Lei $n^{\circ} 9.394$, de 20 de dezembro de 1996, que estabelece as diretrizes e bases da educação nacional. Diário Oficial da República Federativa do Brasil, 25 de maio de 2017. Acesso em junho de 2017, disponível em http:// www.planalto.gov.br/ccivil 03/ ato2015-2018/2017/decreto/D9057.htm

Brenner, F., Pianesser, R., Espindola, D. B., Pinto, I., Musa, M., Gouvêa, A., Gallon, R. F. \& Machado, K. S. (2014). Revisão sistemática da Educação a Distância: Um estudo de caso da EaD no Brasil. In: XI Congresso Brasileiro de Ensino Superior a Distância (pp. 1167-1181). Florianópolis, SC. Disponível em: http:// esud2014.nute.ufsc.br/anais-esud2014/files/pdf/128187.pdf

Chizzotti, A. (2006). Pesquisa qualitativa em ciências humanas e sociais. Petrópolis: Vozes.

Freitas, M. D. C. D. (2007). Dificuldades e limitações da Educação a Distância no Brasil. In: VII Seprosul Semana de Engenharia de Produção Sul-Americana (p. 1-8.). Salto, Uruguai. Disponível em http:// www.kmbusiness.net/images/SEPROSUL_EAD\%20DIFICULDADES.pdf

IFSC (2017). Resolução CEPE/IFSC n4, de 16 de março de 2017. Estabelece diretrizes para a oferta de cursos e componentes curriculares na modalidade a distância na Educação Profissional e Tecnológica de Nível Médio, de Graduação e Pós-Graduação, no âmbito do IFSC. Disponível em https://sig.ifsc.edu.br/sigrh/ public/colegiados/filtro_busca.jsfo_normas/resolucao_n_1_11032016.pdfIFSC/Cerfead. (2017). Acesso em agosto de 2017, disponível em http://www.ifsc.edu.br/ensino/menu-cfead

Lengler, F. R., Dalmau, M. B. L., Silva, E. C. \& Avila, S. L. (2016). Compreendendo a importância das competências docentes na Educação a Distância: um olhar sobre um curso superior de tecnologia. EaD em Foco, 6(2), 77-92. Disponível em http://eademfoco.cecierj.edu.br/index.php/Revista/issue/ view/12/showToc 
Medeiros, J. M. (2017). Tensões e desafios para institucionalização dos cursos técnicos a distância do Instituto Federal de Educação, Ciência e Tecnologia de Brasília. In: IV Colóquio Nacional e I Colóquio Internacional - A produção do conhecimento em Educação Profissional (E1A54). Natal, RN, Brasil. Disponível em https://ead.ifrn.edu.br/coloquio/anais/2017/trabalhos/eixo1/E1A54.pdf

Ministério da Educação. Secretaria de Educação a Distância (2007). Referenciais de qualidade para educação superior a distância. Brasília: MEC/SEED. Disponível em http://portal.mec.gov.br/seed/arquivos/pdf/ legislacao/refead1.pdf

Moran, J. (2003). Educação on-line. São Paulo: Loyola.

Novello, T. P. \& Laurino, D. P. (2012). Educação a Distância: seus cenários e autores. Revista Ibero-americana de Educação, 58(4), 1-15. Disponível em https://rieoei.org/historico/deloslectores/4832Novello.pdf

Sebastião, A. P. F. A (2015). Utilização do ambiente virtual de aprendizagem Moodle em uma instituição de ensino superior pública. Revista Profissão Docente Online, 15(32), 131-139. Disponível em: http://www. revistas.uniube.br/index.php/rpd/article/view/838/1135

Veiga, I. P. A. (Org.) (2002) Projeto político-pedagógico da escola: uma construção possível. 14a ed. Campinas: Papirus. 